\title{
Modernizing the flow of blood: Biomedical technicians, working knowledge and the transformation of Swedish blood centre practices
}

Boel Berner and Maria Björkman

Journal Article

\section{Tweet}

N.B.: When citing this work, cite the original article.

Original Publication:

Boel Berner and Maria Björkman, Modernizing the flow of blood: Biomedical technicians, working knowledge and the transformation of Swedish blood centre practices, Social Studies of Science, 2017. pp.1-26.

http://dx.doi.org/doi/10.1177/0306312717693464

Copyright: SAGE Publications (UK and US)

http://www.uk.sagepub.com/home.nav

Postprint available at: Linköping University Electronic Press

http://urn.kb.se/resolve?urn=urn:nbn:se:liu:diva-135321

I..U 


\title{
Modernizing the flow of blood: Biomedical technicians, working knowledge and the transformation of Swedish blood centre practices
}

\author{
Boel Berner \\ Department of Thematic Studies - Technology and Social Change, Linköping University, \\ Sweden
}

\section{Maria Björkman}

Department of History of Science and Ideas, Uppsala University, Sweden

\begin{abstract}
The early 1980s saw a 'paradigm change' in how donated blood was handled and used by blood centres, hospitals and pharmaceutical companies. In Sweden, a five-year state-financed R\&D programme initiated a swift modernization process, an alleged 'revolution' of existing blood centre practices. In this article, we use interviews and archival material to analyse the role of female biomedical technicians in this rapid technical and organizational change. In focus is their working knowledge, or savoir-faire, of blood, instruments and techniques. We give a detailed analysis of technicians' embrained and embodied skills to create safety in blood and its representations, handle contingencies and invent new procedures and techniques. These transformations are analysed as sociomaterial entanglements, where the doing and undoing of gender, sociomaterial practices, hierarchies of authority and expertise, and emotions are intertwined.
\end{abstract}

\section{Keywords}

biomedical technicians, gender, savoir-faire, sociomateriality, skills, blood centres

\section{Correspondence:}

Boel Berner, Department of Thematic Studies - Technology and Social Change, Linköping

University, SE-581 83 LINKÖPING, Sweden

E-mail: boel.berner@liu.se 


\section{Introduction}

Since the late 1970s, a diverse array of laboratory studies have observed the mundane, everyday activities of scientists in the laboratory and - in the words of Amsterdamska (2008: 205) closely analysed 'what scientists are doing when they prepare, devise, or conduct their experiments; collect and interpret data; discuss, formulate, or write up their work; and agree or disagree about their findings.'

But many laboratories do not do science, and not everybody in a laboratory is a scientist. The main purpose of some laboratories is not research but the preparation of specimens for further analysis by scientists (Barley and Bechky, 1996; Packer, 1996; Wylie, 2014), the production of prostheses such as dentures (Torbica and Krstev, 2006), or the analysis or preparation of bodily substances for further use by hospitals and biomedical companies (Casper and Clarke, 1998; Scarselletta, 1993). Such work is performed by laboratory assistants or technicians. It provides necessary input into the work for those in superior social positions scientists, directors, engineers - but is seldom analysed in itself, nor is it given much attention in most analyses of scientific or technical change. Thus, in his 1989 article 'The invisible technician' Shapin argued that historians 'have shown little inclination to study the role of technicians or other support personnel involved in making and recording scientific knowledge' (Shapin, 1989: 554). Sociologists, too, argues Barley, have largely overlooked the contributions of technicians within science, technology and medicine; moreover, 'sociology's tendency to place theory before description has left us with anemic images of technical work' (Barley, 2005: 376).

In this article we want to counter this 'anemic' image, and in more ways than one. We look closely at the mundane everyday activities of biomedical technicians - almost all women within blood centre laboratories, where they analyse, squeeze, pipette and centrifuge blood for further use within hospitals and the pharmaceutical industry.1 We focus on processes of modernization of blood centre work during a crucial period in the early 1980s. This was a time of 'paradigm change' in how blood was collected and used; it would transform the blood industry for decades to come (Farrugia, 2011: 218).2

Blood centres are crucial nodes for hospital care. By the 1970s, millions of transfusions were being made worldwide. Human blood was also used in a multi-billion dollar multinational blood product industry based on innovations in the collection and fractionation of blood plasma. By the late 1970s, however, this system had serious problems, in Sweden and elsewhere. Hospitals were transfusing blood in inefficient ways, and blood centres were using non- 
standardized and sometimes unsafe methods. The rich world imported from developing countries, such as Nicaragua, Haiti and India, much of the plasma needed to manufacture necessary blood products, such as albumin, immunoglobulin and Factor VIII (the plasma fraction used to increase the life expectancy and quality of life for haemophiliacs). This trade continued, despite the risk for viral Hepatitis B transmission and despite being condemned in 1974 by the International Red Cross as a 'new mode of exploitation of the most needy ... a dangerous, scandalous and unfitting traffic' (Starr, 1998: 246). In 1975, the WHO and its member states issued a strong recommendation that rich countries should attain self-sufficiency; in other words, they should stop this trafficking in blood (Starr, 1998: 246).

In Sweden it would take until 1979 before a state-financed five-year programme, costing SEK 20 million, or about US\$ 11 million in today's currency, was launched to live up to this promise. It is here referred to as the 'STU programme', from the initials of the responsible state organization, Styrelsen för Teknisk Utveckling (the Board for Technical Development). The programme initiated technical and organizational change. It involved pharmaceutical companies, physicians, scientists and blood centre personnel, and was later evaluated as highly successful. The Swedish blood system was, according to the programme's final report, transformed from being wasteful and inefficient into 'one of the most efficient in the world', as the country went from $20 \%$ to $85 \%$ national self-sufficiency in plasma (STU, 1985: 14). Doctors now transfused blood components instead of whole blood, efficient methods of blood component production and quality control were introduced in the blood centres, automation was used on a larger scale and work practices became standardized across the many small and large blood centres. This modernization was hailed by STU administrators as a technical and organizational 'revolution' for the blood centres (STU, 1985: 10).

'Revolution', as we interpret this evaluation, means that a previous development path was interrupted, and skills, tools and practices based on established norms and priorities were discarded, reconfigured or substituted for new ones. Blood centre technicians were at the centre of these upheavals. The programme's final report duly noted their 'commitment' to making the transformation possible (STU, 1985: 10) - but what this commitment consisted of was not deemed interesting enough to spell out; it was left invisible by STU.

The remark, however, made us curious. What happened when technicians were enlisted to transform blood centre practices? What skills were made redundant, which new procedures had to be learnt? Did their knowledge influence the course of modernization? And - since most technicians worked in environments characterized by gendered hierarchies of authority and 
expertise - did their commitment lead to any lasting reordering of gender relations in the blood centres?

Our analysis, based on interviews, documents and archival material, gives insights into how processes of modernization affect operator skills in the biomedical field. Modernization is here seen as the replacement of ad hoc and manual procedures with automated, standardized and research-based ones, considered to be more 'rational' and efficient. The case also illuminates the other side of the coin: how operator skills and innovations may influence technical transformation in the laboratory. In an open and turbulent situation, a window of opportunity was created for ambitious women technicians. Their skills were enlisted to help implement new procedures, standardize work, and even devise some crucial new technical solutions. We follow Pecis (2016) in seeing innovation as a gendered and relational process, based on interactions among networks of people constituting innovation at the micro-level. In this case, it means teasing out the entanglements (Jones, 2013) of everyday sociomaterial practices in the blood centres: the interpenetrations of blood, plastic bags, microscopes and centrifuges with human action, emotion and gendered hierarchies of authority and expertise.

\section{Knowing, handling, changing sociomateriality}

Technicians' skills are here not seen as more or less finite bundles of competences needed for a job and/or inherent in the worker; such a perspective fails to grasp how individuals understand and handle a variety of concrete situations. Instead, we are interested in technicians' ongoing and situated practices of knowing when interacting with the social and material world, in knowledge as something individuals $d o$, rather than as something individuals have (Cook and Brown, 1999; Duguid, 2005).

In line with this perspective, we use the concept of working knowledge, or savoir-faire, as discussed by Barcet et al. (1985). Blood centre technicians' savoir-faire is culturally specific and institutionally defined and also intertwined with the materiality of the blood centres: the veins of donors, the plastic bags, pipettes, microscopes and centrifuges, the gentle shaking of blood bottles and the humming of the air conditioner. It relates to the materials handled in the blood centres, such as human blood and blood components, glass, plastic, and paper printouts, as well as to the flow of work and the various machines, implements and instruments used. Thus, it is a sociomaterial practice, which we, following Leonardi, see as the enactment of activities 'that meld materiality with institutions, norms, discourses, and all other phenomena we typically define as "social"' (Leonardi, 2012: 42; see also Jones, 2013). 
Notions of 'articulation work' and 'bricolage' are appropriate to understanding how technicians intervene in the sociomaterial assemblages of their work. Bowker and Star (1999: 310) define articulation work as 'work done in real time to manage contingencies: work that gets things back on track in the face of the unexpected, that modifies action to accommodate unanticipated contingencies.' It can also be seen as 'housekeeping' (Garforth and Kerr, 2010: section 3.9) - tasks, activities and roles dedicated to the reproduction and maintenance of a laboratory and that include taking care of workspaces, materials and technological equipment. This is work disproportionally undertaken by women, and it is frequently undervalued. It is often routinized and repetitive but, we argue, it may also enact reflection, experimentation and improvization, which may lead to lasting sociomaterial change. Thus, and according to Barcet et al. (1985), workers in certain situations are able to use their savoir-faire for interventions in the work process. Their improvements may be acknowledged and rewarded in a permanent and systematic manner; their savoir-faire may then function in a truly innovative way. Akrich (1998) distinguishes four such user modifications: shifting the usage of an object without changing it, adapting it to new circumstances without changing its primary functions, extending its functionality by adding one or several elements, and diverting it to serve new purposes not included in its original design. The notion of bricolage is useful to understand this dynamic, tinkering aspect of worker interaction with the material world: as making do by using the resources at hand and combining them for new purposes (Gherardi and Perrotta, 2013).

To understand the details of this dynamic, we use Blackler's (1995) terms embrained, embodied, encultured, encoded, and embedded knowledge. Embrained knowledge relies on conceptual skills and cognitive abilities to understand, for example, how blood cells behave in different media. The biomedical technicians in our study combined such elementary theoretical insights with an embodied knowing based on practical training and long experience. Embodied knowledge relies on semiotic cues - smell, weight, colour, etc. - as well as sensory-motor skills and rules of thumb (cf. Barley and Bechky, 1996; Scarselletta, 1997; Wylie, 2014). Encultured knowledge refers to how 'things are done here' - the local codes of conduct that may take the form of stories, metaphors or 'vademecums' about how to handle everyday tasks or problems (cf. Orr, 1996). As we shall see, these may run contrary to knowledge encoded in books, manuals, signs and symbols. One important task for the STU programme - and for some technicians interviewed below - consisted precisely in replacing local embodied and encultured knowing with an encoded, standardized version for all Swedish blood centres.

Embedded knowledge, finally, still according to Blackler, resides in systemic routines, in spatial layouts and interactions, and - we want to add - in the more or less taken for granted 
social hierarchies and patterns of interaction in the workplace. As detailed by Keefe and Potosky (1997: 54), technicians ‘often operate within an established profession's field of knowledge and competence'. Their work allows those above them to 'hive off' the routine and less interesting tasks. This may result in a blurred identity: technicians may be highly skilled but lack formal control of their tasks as they work within the orbit of a dominant parent profession.

Of particular interest to us is the gendered character of this hierarchy - the notion that there is an authority and status hierarchy between those with scientifically 'legitimate' and innovative (male) knowledge and those with 'peripheral' or mainly adaptive (female) knowledge (Truss et al., 2012: 738-739). If this is so, how is this hierarchy enacted? Can it become upset or blurred, and in what kinds of situations? Research on doing gender 'often implies that gender inequality is invariant and that the degree of inequality is irrelevant. However, it is critical to acknowledge and examine that variability so that we can understand the conditions under which change for the better occurs' (Deutsch, 2007: 113). In line with this suggestion, we attend to the modifications in gender relations that may happen when men or women do not follow traditional scripts - when they 'undo gender'. Specifically, we will discuss the sociocultural circumstances that, in our case, made some women renegotiate established definitions of gender and technical expertise, and become active agents of technical change (cf. Wajcman, 2004). Following Bartlett (2008), we will also focus on the 'recruitment of sentiment' - the 'commitment' lauded by the STU directors - which enrolled innovative (female) technicians in the rationalization of the blood centres. Whether this meant a genuine transformation of existing hierarchies of gender and expertise or was only a case of a few women transgressing established boundaries (Gerson and Peiss, 1985: 323) is something we will return to later in this article.

\section{Making experience visible}

Technicians as a professional group have left few conventional records of their lives and careers, and are rarely described in histories of biomedical science (Russell et al., 2000:238). They seldom leave material records in archives, write reminiscences or receive obituaries. Women technicians are even more anonymous and invisible. The only feasible way to fill this gap in the historical record, Russell et al. argue, is through oral history. In this vein, we conducted semistructured interviews (in Swedish) with blood centre medical technicians and directors who were active in the 1970s and 1980s. In 2012, we interviewed 14 women technicians, some in groups and some individually. We started out with two technicians we already knew, and the other interviewees were found by chain-referral. In contrast to the situation in, for example, Britain (cf. 
Hartley and Tansey, 2014), most biomedical technicians in Sweden in the period relevant to our study are and have been women. They work in what traditionally were very hierarchical environments, dominated by male doctors, directors and scientists - but, interestingly, the interviewed technicians did not explicitly discuss gender as a limiting factor in their work. They had worked in small or medium-sized blood centres as well as in the major regional centres; several had become blood centre section leaders. Additionally, four former regional blood centre directors (one of whom was a woman) with long experience from different parts of Sweden were interviewed in 2011, 2012 and 2014, and two former STU directors in 2011. The interviews lasted between one-and-a-half and three hours and were audio recorded and transcribed. The interviewees were given an opportunity to comment on and add to the transcribed version.

Our interviews with the technicians focused on their careers and experience of the changes introduced during the STU programme (1979-1984). Interviews with the blood centre directors and STU administrators also included questions of management and coordination. This generation of technicians had varied backgrounds. Some had a two-year theoretical and practical lab assistant educations behind them, others had a nursing background and/or had taken courses in transfusion medicine and blood group serology while working in the blood centres. We are aware that autobiographical stories are constructed from the interviewees' present social and life position, which, together with the interview process itself, colours their accounts; they are also, by necessity, partial. The interviewees sometimes found it difficult to pinpoint exact times and extent of changes. We have therefore supplemented their accounts with contemporary published and unpublished documents. 3

In this article, two of the interviewed technicians, for reasons that will become obvious, will be presented with their full names; other informants will be quoted with anonymized initials. The material was analysed with the intention of looking for themes related to sociomaterial practices, expressions of skills and social relations at work, as well as the most important changes occurring in the technicians' work and careers (cf. Ryan and Bernard, 2003).

Blood centres are unique in that their therapeutic and industrial raw material - blood - is extracted from a large number of human individuals who are voluntary and most often unpaid donors. The collected blood is then analysed and processed in various ways before being transfused to patients or used within the blood product industry. In the early 1980s, Sweden - in contrast to the situation in many other European countries (Berner, 2012; Healy, 2000) - had a decentralized system of blood donation, with 90 hospital-based blood centres. Nine major regional centres were medically advanced and were responsible for the smaller centres in their region. At the largest centre, in Stockholm, about 60,000 blood units were collected every year; 
at the smallest ones, only a few hundred units per year (Berner, 2012: 145). Close to 2000 lab assistants worked in the Swedish blood centres in the mid-1980s.4 Our informants had worked at small centres with only two to four technicians and a few nurses and also at larger centres with 10-16 technicians, with several nurses and medical doctors.

In what follows, we leave aside technicians' work of recruiting and interacting with donors and focus on their handling of blood and blood components (even though at the smaller centres they did both these kinds of tasks). We will first discuss the savoir-faire needed to handle and classify donated blood, and the changes in technology and procedure before and during the STU programme. We will then turn to the quite complex new task of component preparation: how in the late 1970s and early 1980s it was introduced alongside all other tasks in the blood centre, further developed, and institutionalized across the country.

\section{Modernizing laboratory practices}

In blood centres, donated anonymous blood is transformed into ordered, categorized information about blood groups, antibodies, plasma content, haemoglobin levels, etc. Technicians are responsible for creating correct representations of the blood and for the quality and safety of the material entities that they handle. Both must function as unproblematic inputs into the further work at the hospital and the pharmaceutical industry.

Thus, as noted by Barley, technicians stand 'with one foot in the material world and the other in a world of representations':

[They] employ technologies, techniques, and the knowledge at their disposal to transform material entities into signs, symbols and indices .... Yet, technicians do more than simply generate signs: They [are] ... also responsible for taking care of the entities from which they coax ... information. (Barley, 1996: 418)

By the late 1970s, the handling of whole blood for transfusion was a routine practice at Swedish blood centres. Still, many things could go wrong, including bacterial growth, contamination, the confusion of blood groups, and allergic reactions. The technician might be distracted by other tasks, use defective or inappropriate material and instruments, or do things slightly wrong, thereby increasing the risk of confusion or contamination by, most importantly, Hepatitis B. Standard solutions to all small and large problems that inevitably arise in a blood centre could not be specified in advance, since settings differed widely in terms of size, technology and workload, as well as in the number and competence of the technicians employed. 
Work at the centres was done, our interviewees noted, according to local vademecums, that is, short instructions to 'do this, then this, then this':

It functioned OK but you did not have the whole picture ... why you did it like this, what would happen if something went wrong, or if you departed from the instruction. That was not included. (MS)

[The instructions] said what you should do, but never 'you must absolutely not do this or that'. (RW)

Many everyday decisions were left to the discretion of the technicians. Our informants described a varied type of work in the laboratory. It was routine and tedious but also challenging and interesting. As one technician phrased it, '[t]raditionally, you work a lot with your hands in a blood centre. You see what you are doing, you know what happens in the test tubes, you read off and evaluate and interpret and use your knowledge' (BJ). The technicians pointed to the necessity of sometimes taking shortcuts to get the work done, but also to routine caretaking practices to avoid errors: double-checking, extreme cleanliness, tinkering with the instruments to make them more reliable, using a number of clues when interpreting instruments and information, and using gloves and working in specially designated areas to avoid contamination. They prided themselves on their vigilance and care, including in difficult circumstances: 'it's in our spinal cord [how to work safely]' (NY). The materiality of the objects was, thus, inseparably entangled with the technician's commitment and embodied identity as a skilled performer.

\section{Creating safety in the laboratory}

The work would gradually, but also radically, change over the following decades. As one of the technicians interviewed phrased it: 'I think that nobody in a blood centre will ever experience such upheavals as what we have been part of' (LT). Well into the 1970s, some blood centres still used what the technicians called an 'open system' for the handling of blood, something that demanded strict vigilance on their side. Without attention, the bottles might overflow at donation - a 'nightmare' according to one informant (BK) - or they could break despite having been checked before use.

When I started here, donors gave blood in glass bottles of $450 \mathrm{ml}$, which stood shaking in a shaking machine. There was a riser pipe with a needle in it and a needle in the donor's arm. Then, if you had a lot of work to do - if you had many donors and worked 
all alone with only one assistant - it sounds horrible - but the blood might suddenly start spouting from the riser pipe. And you were not there. (LT)

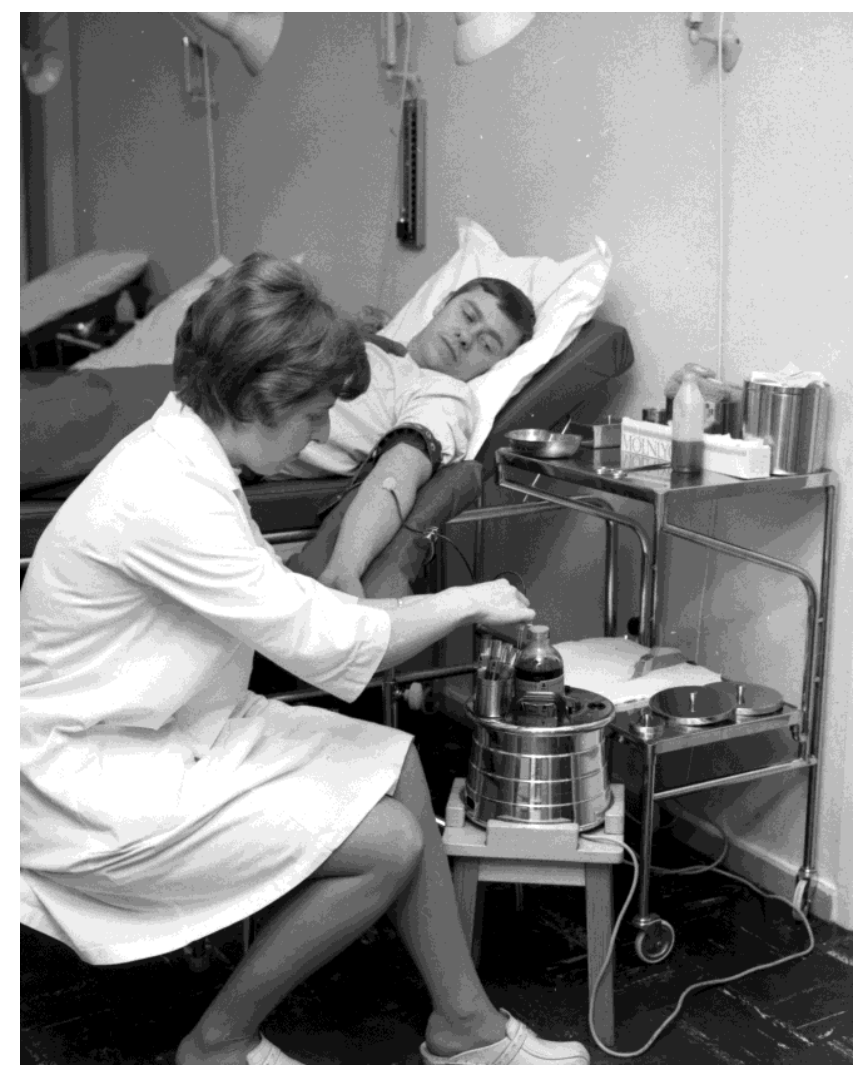

Figure 1: Technician drawing blood

In the 1970s, all tests made on donor and patient blood entailed open handling in glass bottles, as well as mouth pipetting of the blood.5 'The laboratory part of our work was messier at the time,' one informant recalled (LW).

We took blood samples in open tubes. We mouth pipetted serum or plasma, and added reagents that we made ourselves. We had glass pipettes that we cleaned ourselves. The sterilization was not all that great; we heated the tubes in incubators and made sure they were as clean as possible. (NY)

These procedures had to be monitored carefully. Objects had agency when provoked by the actions of the technicians, but matter also had an independent power to contaminate, confuse and destroy (cf. Leonardi, 2012). 'The glass tube often broke where you put in the cork - and then you cut your finger. We didn't use gloves at the time' (LW). Certain reagents were carcinogenic, and the risk of contamination from patient or donor blood was always present in the technicians' 
minds. Our informants tell stories of how they, or their colleagues, had to rush to the sink to spit and rinse their mouths when they inadvertently sucked in blood when mouth pipetting. Despite being careful, technicians would become contaminated with Hepatitis B when handling blood in the clinic or the lab. As one technician remembered, this led to something like a 'mass psychosis' in the lab, with technicians checking their eye whites every day. They sometimes had the impression that these had turned 'yellow as a canary bird', even when this was not the case (LT).

To protect both themselves and patients, some technicians at a small centre decided to check all their donors for markers for Hepatitis B. There were no tests available at the time, but they knew that a heightened level of a certain liver enzyme might indicate contamination. The supervising medical doctor was largely absent, so the technicians decided on the matter themselves. We see this as a strong example of how technicians used their embrained savoirfaire to adapt practices to a local, immediate situation.

Hospital authorities also introduced safety measures, such as marking kidney patients' blood samples with a yellow triangle (for contamination risk) to indicate that they should be handled with safety clothing and gloves on. Something called the risk bench (or Hepatitis bench) was introduced, where the technicians were to use a protective coat, a visor and what were then called 'sausage sleeves', protective sleeves of the kind that hot dog sellers used to wear. The use of gloves and other means of protection was not a self-evident routine, however, but a situated and even contested practice - 'a matter of culture and competence', as one informant phrased it (AS). Local codes of conduct made for differences between hospitals in the handling of blood:

Gloves cost money. Nobody in the hospital in XX said they should be used... We used an ordinary cannula of the kind you put on a syringe, and placed it in the patient's vein [to take blood samples for laboratory tests]. And then you put your thumb in the way so that the blood would not spout and filled an ordinary test tube without a cork. I developed quite a knack for filling that tube without spilling any blood. (BO)

In the neighbouring city, where she later worked, gloves and sterile vacutainer tubes (using vacuum in a closed system, thereby facilitating the draw of a predetermined volume of liquid) were standard. But even in blood centres where gloves were common, they had to be used with discretion and vigilance. Mouth pipetting could not be done with gloves on since a finger had to be used to stop the blood, and you could not get it tight enough with a glove on. Gloves were also often deficient. They would last only between 10 minutes and four hours, depending on the work being done, before ripping or becoming thin. Using gloves could even increase the risks, since they gave a false sense of security: 
If you use gloves but handle binders, door handles, telephones [with them on] - then you only protect yourself. Your skin is very sensitive; you notice if you spill blood on it. But you don't feel the spill if you have gloves on - and then the spill might get just anywhere. (BJ)

\section{Creating representations}

Blood was to be safely collected, stored and distributed to hospital wards. It also was to be translated into reliable signs, symbols and indices. In 1978, 150,000 blood typings were made at the Stockholm blood centre alone, as well as 114,000 cross-matchings (STU, 1979: 57). All results were to be secured by repeated controls. Donors and patients were tested for various diseases and conditions (haemoglobin level; sedimentation rate; hepatitis; syphilis; more recently, HIV). 'Sometimes we had to make fifteen to twenty different tests just from one blood sample from a patient', one informant recalled (NY). Much work - including blood typing, testing for antibodies, blood counts and so on - was done manually, because in the late 1970s there were no machines suitable for small blood centres. 'The work involves many repetitive moments which nevertheless must be performed with a high degree of accuracy', one blood centre director reported to the STU programme in the early 1980s (cited in Berner, 2012: 152).

The interviewed technicians remembered a messy and time-consuming practice:

Initially, there were glass plates and small test tubes, and you had to first incubate them [at $37^{\circ}$ ] in an incubator for an hour, then wash them four times and then drip on, then centrifuge it, then read off... and then you poured it on a slide to look at under a microscope ... It was quite time-consuming to do this for every analysis, every single patient sample. (MS)

It is impossible to describe all that mush and slush, so when the gel cards came [in the 1990s] it was so much easier to handle, even manually. (RW)

From the 1970s onwards, and partly as a result of the STU programme, there was a gradual introduction of 'closed' systems when handling and interpreting blood. Plastic bags were introduced. 'In the serology lab, first we stopped using glass bottles, then pipettes that we rinsed. Instead we got disposable pipettes .... Mouth pipetting disappeared, too.' To this point, modernization meant semi-automation. Large blood centres started using versions of a machine called the AutoAnalyzer for blood typing and antibody screening. The device eliminated a lot of time-consuming work and made for accurate and reproducible antibody quantification. 
Screening was here made in a closed system, but some manual work was still needed to load the machine with blood, sera and reagents, and it was a mental challenge to interpret the curves produced by the machine.

Working with machines demands sensory and motor skills, vigilance and judgement (Berner, 2008). As discussed by Doing (2004: 308), technicians are deemed by those above them to possess 'lab hands'- a 'feel for equipment' that enables them to sense problems and get machines working in an almost intuitive way. This idea also surfaces in our material in connection with a blood-grouping machine called the Groupamatic. It was introduced in the 1970s, together with a mini-computer and a system of coloured punch cards in the 'Scandinavian blood group colours'. According to the blood centre directors in charge, this automatic procedure

called for a good understanding and judgement of the operators. Interpretation and management of errors, which can occur during the run, will be very difficult unless the technicians have a very thorough knowledge of basic blood group serology. (Messeter and Löw, 1977: 125)

The Groupamatic machine demanded that technicians could 'work efficiently at the processing speed of the machine and perform the different tasks (often simultaneous) required by the machine' (Muller et al., 1981: 211). The machine was also quite difficult to handle in case of trouble (Messeter and Löw, 1977: 125). Machine breakdowns can have dramatic implications for the work of biomedical technicians, since physicians at large hospitals require laboratory services around the clock. Even if, for example, the counting of blood cells could be done manually, it was time consuming (cf. Scarselletta, 1993: 15). Machine malfunctioning was worrying, too, because it increased the probability of reporting incorrect results:

That HB apparatus we had, I got a stomach ache every time I ran it .... It did not feel trustworthy. We had to run a test several times .... It was replaced later because of the low reliability of the measurements. (BT)

Accordingly, the technicians had to develop a knack for troubleshooting and tinkering. One of the interviewed women remembers:

We were in charge of the [photometer] machines and how the curves should look to get as accurate values as possible. That was our area of responsibility; to see to it that there was as high a quality as possible on our samples. So you walked around all the time with a slide rule in one pocket and a screwdriver in the other. (NY) 


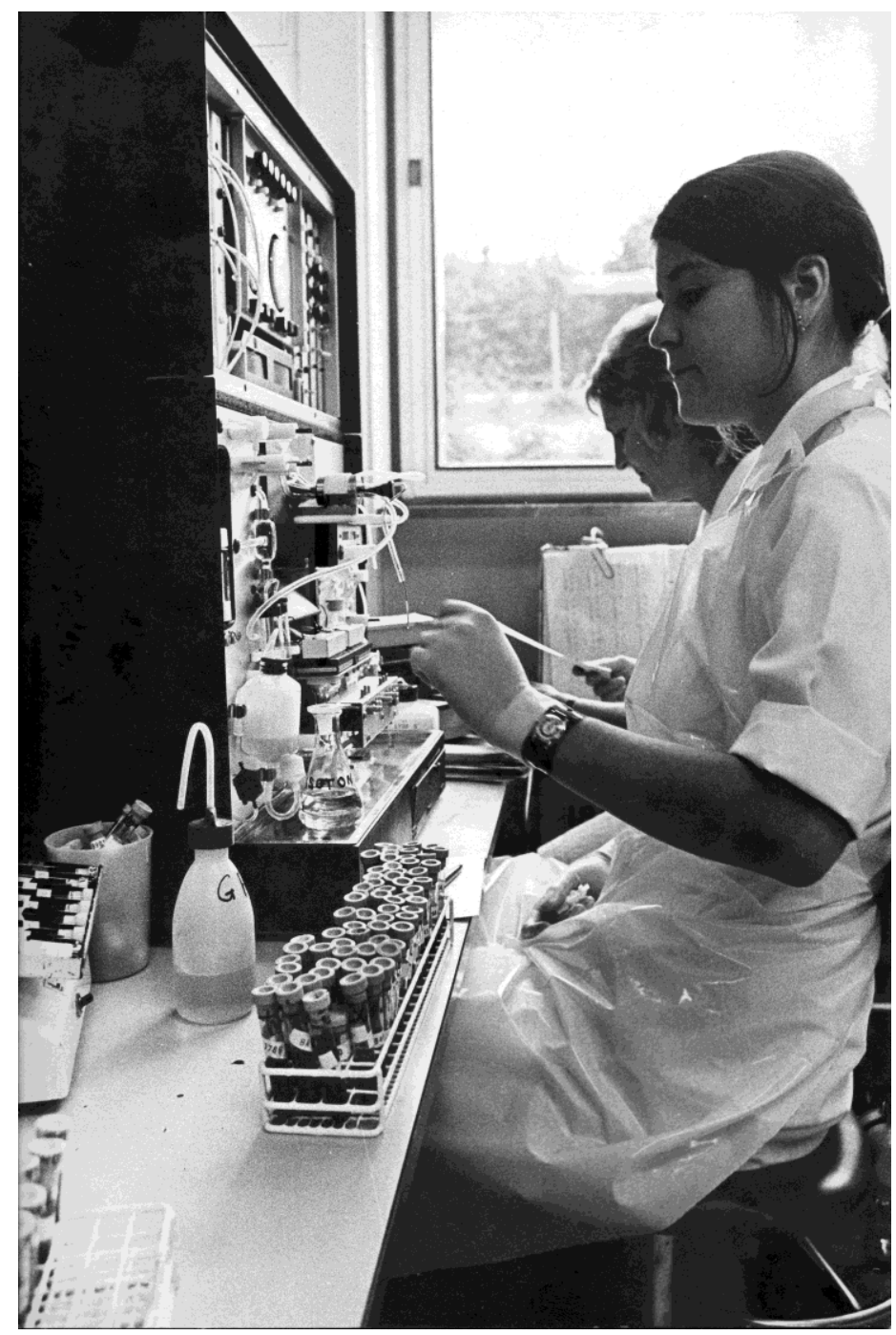

Figure 2: Blood analyser

Our interviewees may have painted a somewhat rosy picture of the skills used to create safety and efficiency in the lab. But Sweden had a decentralized system of blood collection, and conditions differed widely between centres across the country. 'Existing routines were of varying quality, the equipment had deficiencies, and method instructions were often incomplete or lacking', was the verdict from a survey of a selection of centres done in 1979 (STU, 1986: 33). As we discuss below, the STU programme advocated a standardization of practices as one possible solution to these problems; another was increased automation. Also needed, it seems, was 'commitment'. Local technicians had to show a 'positive attitude' to technical change; at least this was how some blood centre directors phrased it:

It is ... our experience that the attitude of the technicians towards automation plays a great role in the quality of the results. A positive interest is more important than in a manual routine, where the shortcomings of one individual can be largely covered and 
controlled by the common effort of the working team. As only two or at the most three persons work with the blood-grouping machine simultaneously, it is advisable that at least one of the technicians have such a positive attitude. (Messeter and Löw, 1977:125)

Thus, 'housekeeping' (Garforth and Kerr, 2010) and other forms of articulation work based on the technicians' interpretative ability, dexterity and 'positive attitude' were needed to create safety, minimize machine mistakes and keep laboratory equipment functioning in an efficient way. They turned out to be even more important when the major change brought about by the STU programme was to be implemented. Complex new techniques to produce blood components from donated blood were at this point to be introduced into all Swedish blood centres, alongside the various tasks described above. What happened gives insights into how gendered hierarchies of authority and expertise are done - and even 'undone' - when lower level workers are enrolled to make procedures work, and sometimes change them.

\section{Introducing blood component production}

Component production means the separation of donated blood into red blood cells, plasma and thrombocytes. All hospitals from now on were to transfuse components, not whole blood, as this was deemed to be medically more efficient. And more plasma was to be frozen straightaway to be delivered to the industry for further fractionation into much-needed blood products such as Factor VIII to haemophiliacs. Several new steps had to be accomplished with every unit of blood in the blood centres and new forms of savoir-faire had to be developed.

You got more tasks to do. Previously, you drew whole blood from the donor and that was all there was to it, and you put it into the blood fridge. Now you had to put the blood in a centrifuge and then remove it from the centrifuge and then separate it - and suddenly you had three bags from the same blood donor. The red blood cells you had to put into the blood bank, the plasma you had to freeze, and then there would be this little bag with platelets, which you had to do something else with. (BO)

All this was a somewhat sticky and sometimes dangerous procedure:

I would say that in the beginning how the bags were used was not very rational either. ... You may have had two bags that hung together. You drew one bag of blood and then to get the plasma into the other bag, you simply squeezed it over. (RB) 
It was really dangerous ... because of the risk of bacterial contamination and such. (BO)

Red cells (erythrocytes) and plasma were first separated from each other; then the platelets (thrombocytes) had to be separated out. Originally, this was done from the plasma (later from the buffy coat, see below). The procedure was largely manual and quite complicated. The bag with the plasma first had to rest for a while and then be re-centrifuged before a certain amount of thrombocytes could be squeezed off from the plasma; how much was estimated manually, by touch and sight. The interviewed technicians agreed that it was difficult to estimate the correct amount of thrombocytes to be squeezed off, and that there was a great span between different technicians depending on where one put one's fingers to squeeze: high up or low down on the bag.

Our informants describe hectic periods where, in order to complete their tasks, they could hardly take any breaks. There was no easy way to speed up the process: 'You cannot hurry up the thrombocytes,' one technician remarked; the bags had to rest for at least an hour before each centrifugation $(\mathrm{RW})$. And the blood could not be spun faster or for a shorter period of time even if you were in a hurry, noted another (BO). There seems to have been little consultation with the technicians about practicalities before component preparation was introduced, but the STU survey noted that there was 'a great deal of uncertainty, especially at smaller blood banks, in face of the prospects of commencing production of components' (STU, 1986: 33). Some technicians in our study remembered how they reorganized the flow of work to cope with the increased workload. The blood centre in question was quite small and all component preparation took place in the same room. The technicians therefore organized a kind of conveyor-belt procedure, where one person centrifuged, another squeezed the plasma, a third weighed the bags, and a fourth put labels on the bags; all rotated between the positions and also did laboratory work.

The technicians also recall situations when their skills were used for innovation. We will here focus on the contributions made by two biomedical technicians. Their experience shows innovation as a gendered and relational process, based on interactions among networks of people at the micro-level (Pecis, 2016). It also illustrates that organizational features matter. Some organizations are more open than others to the creative work of those in subordinate positions, argue Barcet et al. (1985). They found innovative savoir-faire to be more common in small companies with craft-like production and in companies that produced complex means of production, such as precision steel and mechanical and electrical construction. Some Swedish blood centres in the early 1980s, and especially those based in regional and university hospitals, 
can be seen as environments similar to those described by Barcet et al. They were quite small units, had a craft-like production of highly specialized and complex medical material and information and were subject to stringent quality and safety demands. This meant that the competence of everyone had to be enrolled, at least in a period of transition as in the early 1980s. 'We worked as a team', one informant recalled, 'like a family where all members had their specific tasks' (LW). We will return to the 'recruitment of sentiment' that this close involvement rested upon.

\section{Freezing plasma like green peas}

Ann-Margret Swärd-Nilsson (second from the left in Figure 3.) described how she got independent tasks very soon after her arrival at the regional blood centre in the university town of Lund. For example, the director sent her to a centre in the north of Sweden, which was the first to do component separation on a large scale. She was to learn how to separate the blood, bring the knowledge back to Lund, and teach other technicians the procedures.

Swärd-Nilsson had a lab assistant education. She saw herself as a farm girl who was used to handling large quantities of liquid matter, like milk. She therefore preferred working with blood in $400 \mathrm{ml}$ plastic bags, rather than with 'tiny things [in microscopes] that you cannot see with the naked eye'. She had a practical bent and an 'itch' for testing new ways of doing things; sometimes these became the new and improved methods at the blood centre. Most importantly, her director gave her the task of developing a method to rapidly freeze freshly collected plasma: the coagulation proteins needed to treat haemophilia were better preserved the more quickly the freezing was done. Contact was made with a large company in the region that produced freshly frozen vegetables. The company used a method where frigid air was blown on vegetables, such as green peas, which froze them immediately. It was hoped that this method could be adjusted for the freezing of plasma. Swärd-Nilsson collaborated with an engineer from the company to construct a new freezer and test it at a plasma collecting centre in Stockholm. The engineer contributed his know-how about freezing technology and Swärd-Nilsson her conceptual (embrained) and experiential (embodied) knowledge about the properties of blood, how they changed in different storage conditions, and which technical procedures could feasibly be used within the health care sector.

The result was a medical freezing technology that would become standard in Swedish blood centres and elsewhere. Swärd-Nilsson later presented the technique (and other research) in articles in which she was often the lead author. She did not, however, participate in the patenting of the technology and therefore did not draw any economic benefit from her innovation. 


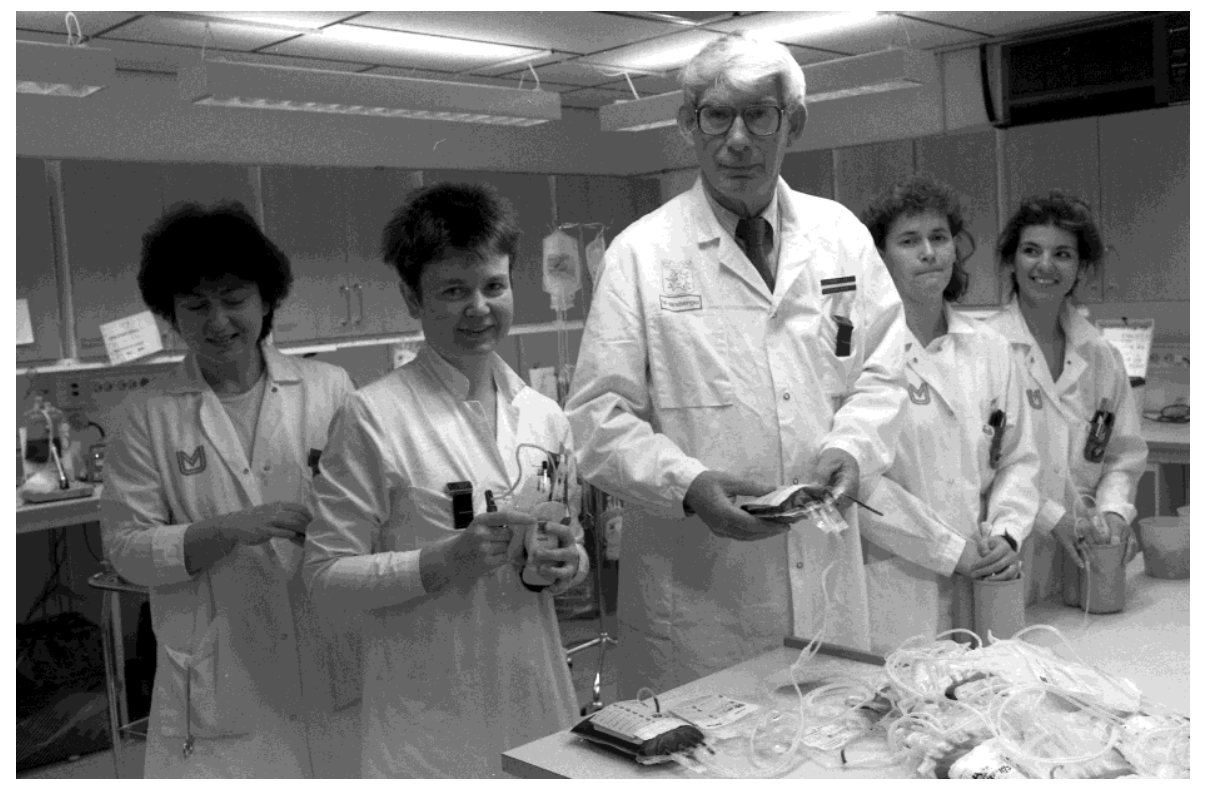

Figure 3: Blood centre staff

\section{Separating sticky components}

The regional blood centre based in another major Swedish university town, Uppsala, was an important node in the STU programme. Its director, Claes Högman, was influential within both Swedish and international blood research. The centre employed a number of physicians and researchers who contributed in important ways to the transformation of the Swedish blood system. As one of them recalls, constant experimental work went on in the centre at the time, for example, about the optimal rotation speed and time of the centrifuge, on how to count thrombocytes, or on which medium was most suitable for the suspension of blood concentrates. The experiments involved the centre's technicians: 'It was a very intense period in terms of component development ... we were very much involved ... and got ... to test all variants. During this period there were new bids every day about what we should do', one recalled. The technicians were included as authors in scientific papers, albeit mostly, she added, as 'a mere helper' (LW).

We will follow the trajectory of one technician who got a more important role, Anne Johansson. She had a lab assistant education and work experience in immunology and serology before arriving at the blood centre in the late 1970s to be employed as section leader. She described herself as a person with 'a creative mind' and her director as a kindred spirit:

He was fantastic to work with .... I would come into his office in the morning [and say] 'Last night I could not sleep. Listen now, I got this exciting idea ...' That got him 
started. ... His interest lay in how to preserve the red blood cells and my interest was in the practical handling of blood. I ... made these products every day, squeezed and pried [the bags] .... What drove me was to simplify the work, but still get a correct result. Yes, I became like [Högman's] extended arm in some ways and did a lot of work that nobody else would otherwise have done.

Anne Johansson was, among other things, instrumental in developing what was to be called MAF-blood (micro-aggregate-poor blood) from blood that, for example, had been collected in mobile units and therefore had not been frozen within the required four hours (and accordingly could not be used for the pharmaceutical industry's production of Factor VIII). This involved a procedure to eliminate the so-called buffy coat, or micro-aggregate, of white blood cells and platelets that after centrifugation forms a thin layer between the erythrocytes and the plasma. If not taken away, the buffy coat might endanger the transfused patient. Johansson got the idea that this 'slush' could be taken out through the tubing used for collecting blood, into a container. The white blood cells from the buffy coat could then be used for interferon production or for transfusion (Högman and Johansson, 1981). As one informant who worked with the procedure described it:

This middle layer of platelets and white [blood cells] ... becomes like a lump, like jelly ... it was like a jellyfish ... a sticky mass. You squeezed it out [with both hands] [into a graduated cylinder] and then you used a suction to suck it up from the cylinder into a slush bottle. (LW)

Johansson got the university hospital's prize for her innovation with the argument that it saved the cost of the filters that were otherwise necessary for getting rid of the micro-aggregate.

By the early 1980s, the production of MAF-blood was standard procedure everywhere. It took about five minutes per unit of blood to produce, more or less depending on the skill of the technician. However, many damaged their hands from the constant manual squeezing of blood bags, some got allergic reactions from the plastic, and the visual clues that the technicians used to squeeze out the recommended $40 \mathrm{~g}$ of buffy coat did not allow for precision work.

During the 1980s the MAF-blood procedure would increasingly be replaced by what was to be called the Sagman system. This method involved a battery of four plastic bags. Through centrifugation and various other manipulations, whole blood was separated into plasma, platelets/white blood cells and red blood cells, each in their own plastic bag together with appropriate chemical solutions to prevent clogging and other problems. The technique was 
developed by Högman and his colleagues, including Anne Johansson. Its rapid introduction as a routine procedure at almost all Swedish blood centres was crucial for the success of the STU programme, since it allowed for a substantial increase in plasma deliveries to the industry; the method gave a 30\% increase in plasma extraction from donated blood (STU, 1985: 6).

Initially, most work with the Sagman procedure was done manually, but Anne Johansson wanted to get rid of the strenuous squeezing and visual checking through automated techniques 'that would work ... for those who had to squeeze the hundreds of bags arriving every day'. She provided the idea behind two important innovations: Optiplate and Optibag, and collaborated with Högman and an engineer in the development of a third, Optipress.

Optiplate consisted of a plastic shield in the shape of a blood bag but with a 'waist' in the middle. Johansson got the idea after having worked with blood bags that, after centrifugation, still contained red blood cells that got trapped in folds of the bag. To solve this problem, she cut out a shield from an empty plastic container and attached it to the blood bag with the help of a rubber band. This was a rather telling example of 'bricolage', seen as making do, using the resources at hand and combining them for new purposes (Gherardi and Perrotta, 2013). In Anne Johanssons's words:

When you put the rubber band around it, the top of the bag became completely distended; this had the result that, after the bag had been centrifuged, a lot of red blood cells would no longer gather in the folds as the bag did not collapse as it did before. Thus, the use of the Optiplate resulted in very little contamination of the plasma by red blood cells; we got very cell free plasma.

Optibag was another of Johansson's ideas. She realized that the red cells could be taken out downwards rather than, as was then done, upwards in the blood bag; this procedure would lessen the risk of contamination. At the same time, she was involved in the more intricate development of the automatic component separator Optipress. This was a machine that pressed out the contents of the blood bags from different ends of the plastic bags (as in the Optibag procedure): erythrocytes downwards and plasma upwards; this was done under the control of a photocell (Johansson et al., 1982). The device - which had several variants - was based on an idea that Johansson got at four o'clock in the morning and for which she got the support of the director of the blood centre. Plastic bag manufacturers and the Pharmacia biotech company were enrolled in the project, and the university workshop made the first machine prototype - a rather awkward apparatus that the technicians at the centre tested out in its different variants. A patent application was filed and the machine was later put into production and general use. 

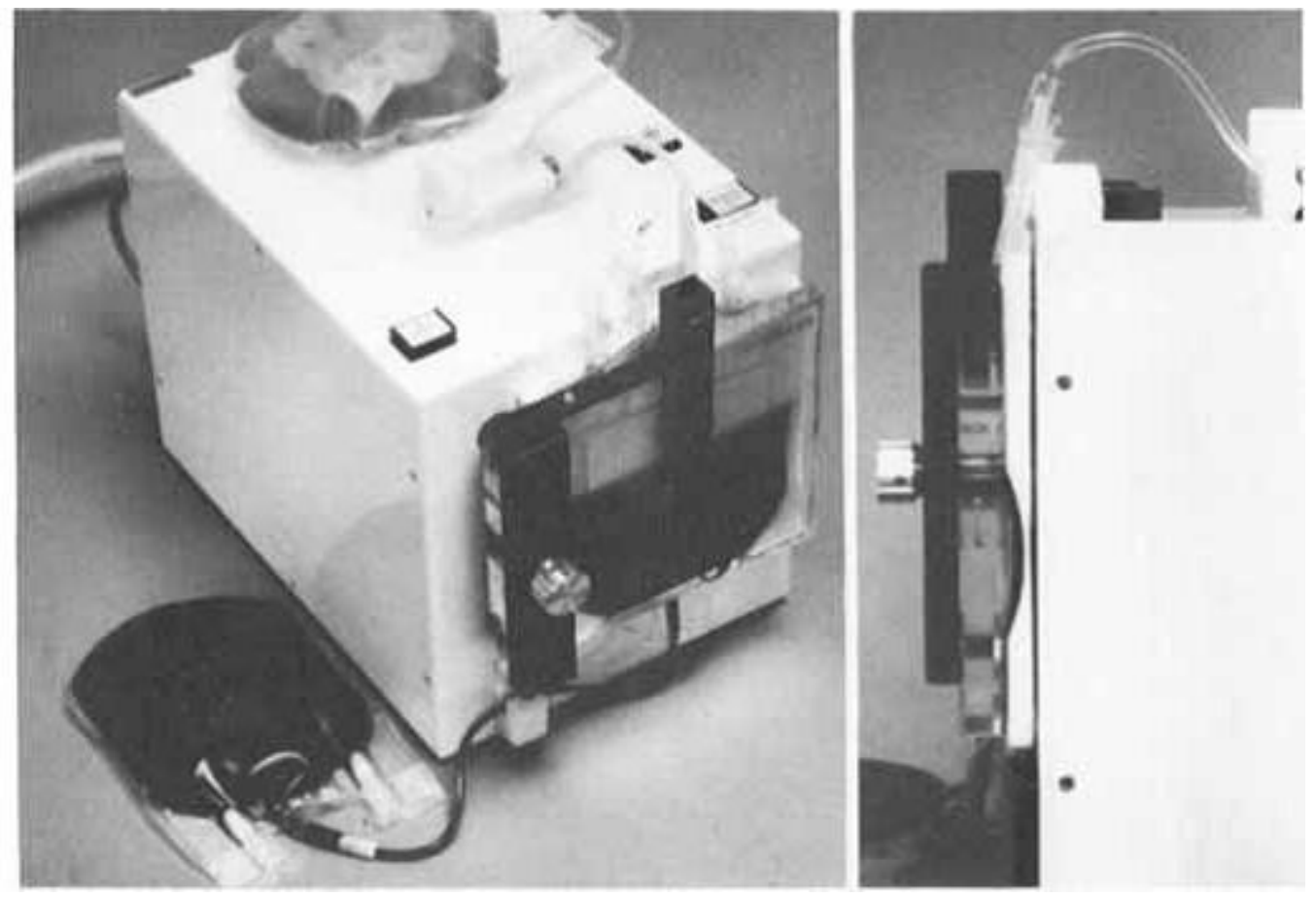

Figure 4. Optipress with blood unit, and profile of the Optipress at the end of the procedure (Högman et al., 1988: 212).

Anne Johansson's innovations were based on a combination of theoretical, embrained, knowledge of blood and blood components, embodied experiences of the practical difficulties of component production, and local tinkering and bricolage. Similar to Ann-Margret SwärdNilsson, her savoir-faire became embedded in new routines and machinery. Her expertise was acknowledged and - in contrast to Swärd-Nilsson - she also reaped some economic benefit from the patenting and production of the Opti system.

The Sagman and Opti systems, with their closed and increasingly automated procedures, meant greater efficiency and fewer work hazards for the technicians. They may also have meant more routine work in the blood centres. Indeed, Högman and colleagues (but not Anne Johansson, who had by then left the centre, because she had less interesting work when she returned from her parental leave) later described as one advantage of the Optipress that it could be handled by less-qualified personnel. Previously, the article noted, 'a trained technician' needed quite a lot of time to manually handle the process. Now four to six machines could be loaded at the same time and 35-40 component sets could be handled every hour. '[T]he laborious technique to squeeze out the buffy coat manually ... has ... been replaced by a devicecontrolled procedure which improves accuracy and reduces the need of technician skill and labor' (Högman et al., 1988: 217). Thus the interventions by concerned technicians to facilitate 
blood centre work may have deskilled the jobs of many of their colleagues. A similar unintended effect may have resulted from another major effort within the STU programme: to improve local performance through the standardization of techniques and practices. Here also, some technicians were deeply involved.

\section{Standardizing local practices}

As noted above, quality and safety standards varied greatly between centres, a problem that became exacerbated by the new demands to produce plasma for the industry. Anne Johansson was recruited to do a survey of existing procedures. She recalls an almost touching welcome from technicians at smaller centres when she and her colleague (a male serology expert) arrived:

Everyone did their best, given existing conditions.... But they were often very lonely. They were expected to be able to do everything and manage it all, and they did not get much help ... Where would they get the knowledge from? It was not widespread, after all. Often they had no knowledge of blood conservation, that is, of the survival of different cell types in storage. They drew blood and produced blood components as best they could.

Johansson realized that many technicians were unaware of how their ways of working affected the components. For example, the centrifugation method used in the larger centres could not simply be transferred to the smaller ones; their centrifuges were of a different size and rotation strength. Applying the speed and time used in the large Uppsala centre to a small centrifuge would give non-optimal results - leading, for example, to thrombocytes ending up in the plasma. Anne Johansson and her colleague therefore constructed a simple 'everyman's method'. It used an equation based on a function between time and speed to make a curve on a paper, which could then be cut out and weighed on a scale to find the best settings for the centrifuge in question (Högman et al., 1982). This was a simple, but workable, way for local technicians to accomplish their work with the resources at hand.

A further important tool to enhance local quality and efficiency was a Handbook for Blood Centres, produced by the Swedish Transfusion Association as part of the STU programme (and regularly updated thereafter). It was written by a working group of scientists, blood centre directors and technicians, most notably Ann-Margret Swärd-Nilsson and Anne Johansson. Its recommendations were based on scientific research, experimental work and practical experience, as well as extensive consultation with local blood centres. The intention was - as one blood 
centre director involved remembered it - to 'boil down' the various centres' ways of working to a common 'best way' (PC).

Rules and standards - such as the ones encoded in the Handbook - function as means to shape and discipline local practices. To be accepted, they have to be 'localized' in situated action, to gain what Timmermans and Berg (1997) call 'local universality'. Blood centre directors in Sweden were quite independent, and there was no central government authority with the power to regulate local practices in much detail.6 While one section of the Handbook contained strict minimum requirements for the handling of blood donors, components and equipment such as freezers and centrifuges, another mainly presented examples of good and reliable methods. They were seen 'as recommendations, not as the rule of law', as our informants said. An 'encultured' diversity of local ways to organize blood centre work would therefore prevail until the 1990s. Moves towards accreditation, certification and European standardization would then, according to the blood centre directors interviewed, force all centres to introduce more rigorous standards. For the technicians this meant increasingly detailed control over their everyday work. They went from having a relatively large amount of discretion during the period before the Handbook was introduced, towards greater uniformity from the 1980s onwards, and then to the current system of certification for each and every laboratory and biomedical assistant. As one interviewee described the situation today: 'As a laboratory assistant you do not act on your own, you act according to someone else with a higher degree. ... The technician's role is often very circumscribed and subject to regulations and instructions' (BK). This has made for a variety of strategies to which we now turn.

\section{Changing hierarchies of gender and expertise?}

Men inviting a few women - as illustrated by the cases of Swärd-Nilsson and Johansson - to cross a boundary will not necessarily lead to structural change. Gendered hierarchies are not undone just because some women transgress traditional norms about whose expertise is to be included in a particular situation - especially if the work of others is made more circumscribed and subordinate. Such developments may instead reinforce existing gendered hierarchies (cf. Deutsch, 2007; Gerson and Peiss, 1985; Nentwich and Kelan, 2014). Thus, the further modernization of blood centre work seems to have made for more routine and regulated tasks. A traditional hierarchy based on formal position and scientific expertise - and in large part gendered - has tended to remain.

However, ideological, technical and educational reorderings parallel to the STU 'revolution' have also given technicians access to new roles and tasks. When some of the 
interviewed technicians felt that they had become assistants to rather than collaborators with the scientists, they left, in Herman's (2015) term, for a 'rerouting' of their careers. They became teachers in the newly established university-level educational programmes for laboratory technicians, or - in the case of Anne Johansson - got a degree in economics and later moved to the pharmaceutical industry as an inspector of blood centre quality. Others used their savoir-faire for a 'rebooting' (Herman, 2015) of their careers within the blood centres. Beginning in the early 1980s, experienced technicians could gain a Master's degree and even a $\mathrm{PhD}$ based on their work experience, enabling them to do research or handle the more advanced procedures being introduced in blood centres and other laboratories, along the more routine ones. By then, existing hierarchies of gender and expertise, including within the biomedical sector, were challenged by the feminist movement; these challenges had an impact on legislation and work relations. Modernization, therefore, did not only mean technical change but also new ways of 'doing' and 'undoing' gender in the laboratory. It was a contradictory process, locally negotiated but also intertwined with more general structural and ideological reorderings of authority and expertise.

\section{Conclusion}

We want to take this discussion a bit further. We have, first, made a case for the usefulness of looking at forms of knowing to understand and untangle sociomaterial realities in laboratory settings. We have focused on often-neglected contributions by technicians and on the savoir-faire used in their intimate encounters with the blood, centrifuges, plastic bags, inscriptions, rules and norms that comprise the sociomateriality of the blood centres. Such matter exercises agency through actions that humans cannot completely or directly control: blood splashes and contaminates, blood cells wander, instruments malfunction, gloves and bottles break, plastic bags create allergies. The technicians used their embodied, embrained and encultured savoir-faire to counter such effects, produce and interpret signs, and contain and control problems. Modernization processes may demand new skills and make others redundant, but, as noted by Leonardi (2012: 35), 'even in the face of the most apparently constraining technologies, human agents can exercise their discretion to shape the effects that those technologies have on their work'. The blood centre technicians in our study developed various 'housekeeping' skills to minimize manual and machine mistakes and keep equipment functioning in an efficient way.

Secondly, were blood centre technicians 'doing gender' when they performed what some see as 'feminine' and subordinate tasks - taking responsibility for the well-being of the machinery they operated and care of the blood samples, components and inscriptions they prepared? Or when they performed routine tasks that demanded vigilance and the deft handling 
of pipettes, blood bags and reagents? Such an 'intuitive feeling for the equipment and manual dexterity' can be seen as 'feminine' attributes, assigned by scientists to technicians, argues Doing based on his study of a physics laboratory. This attribution may be made regardless of the biological sex of the technician; instead, the attributes may be taken as indicators of a lack of expertise and justify social control and subordination (Doing, 2004: 309, 315). Similarly, the women cytotechnicians working in Pap smear laboratories studied by Casper and Clarke (1998) had to exhibit 'personal qualifications' - a sense of responsibility, the ability to stay focused for long intervals of time and the visual ability to distinguish fine differences in details. The gender division of labour was such that their job was both low paid and offered 'the worst combination of high responsibility with low or no autonomy' (Casper and Clarke, 1998: 269). Gender and skill hierarchies are, in these accounts, almost by definition deeply entwined: Women tend to stay in subordinate positions, and the skills of subordinates are defined as 'feminine' and, as a result, as unqualified and peripheral, in need of control from those above with a scientific, innovative expertise defined as 'male' (Truss et al., 2012: 738-739).

Our study paints a more complex picture. Medical technicians in laboratory settings operate as what Barley and Orr call 'buffers'. They 'simultaneously link professionals to and shield them from aspects of the material world about which those professionals are presumably experts' (Barley and Orr, 1997: 14-15). As we have seen above, blood centre directors and scientists may have been experts in the science of blood, but they were much less knowledgeable about the day-to-day practical handling of blood samples, plastic bags, centrifuges and the flow of work. They were dependent upon the technicians' manual dexterity, interpretative ability, and visual attentiveness, as well as their theoretical insights into how blood behaves in different circumstances. 'Peripheral' skills were thus central for the safety and efficiency of everyday work and technician responsibility was in many situations coupled with autonomy. Our case shows that defining certain skills as 'peripheral' just because they are used by women is too static; rather, their significance is locally negotiated, as is their use in everyday work.

Timing is important, too, as our case shows. In the early 1980s, strong medical, political and financial pressures made it imperative to mobilize all blood centre personnel, regardless of position, to make Sweden self-sufficient in blood. In this situation, the 'feminine' savoir-faire of lower grade female technicians was as necessary for modernization as the scientific knowledge of those 'with a higher degree'. It could even - at this particular historical moment - be used and acknowledged as a creative force, as an innovative savoir-faire. Through bricolage and tinkering, some technicians, in Akrich's (1998) terms, adapted techniques to existing routines, extended the functionality of existing objects by adding one or several new elements (as in the 
case of the Optibag) and diverted a technical procedure to serve new purposes not intended in its original design (as in the case of the device for the freezing of vegetables). The technicians also invented some truly new assemblages of objects and hands-on procedures, such as the MAF technique, the Opti system, and an ingeniously simple method to calculate the optimal speed of spinning blood, all of which were introduced as standard practices everywhere. New alignments were configured between the social and the material that were 'both localized and able to travel, both stable and reconfigurable, intelligibly familiar, and recognizably new' (Suchman et al., 2002: 164).

Finally, our case suggests the importance of emotions in laboratory work and their intertwining with sociomaterial change. For technicians in the blood centres, producing safe blood for severely ill patients, avoiding contamination, reorganizing tasks and creating new technologies to prevent work injuries were matters of emotional commitment. There was pride in work well done but also fear of contamination, pain due to monotonous tasks, and anxiety in the face of the new. Some had an 'itch' to create, an excitement that kept them awake at night - what scholars have described as a largely masculine orientation towards the power and the pleasure of technical work (Faulkner, 2000). But like the female laboratory technicians interviewed by Packer (1996) - who were positive about the association of technology with power and control, interested in the servicing and repair of the instruments, and who even expressed affection for certain favoured machines - women in our study had a genuine interest in the nuts and bolts of technology. Such a 'positive attitude' towards technical change was applauded by those in charge. Some blood centre directors enlisted it for their own professional ends and/or to make the centre fulfil the STU programme's goals of increased productivity and blood safety. We have shown how this 'recruitment of sentiment' from above (Bartlett, 2008) took several forms: engaging the technicians' interest in being closely involved in a charismatic director's groundbreaking studies, encouraging their 'itch' to create and reform inefficient practices, and using their desire to work together 'as a family' for what was constructed as an urgent task of biomedical modernization. Thus, our case also shows the contradictory, non-innocent and troubling features of how 'matters of care' (Puig de la Bellacasa, 2011; see also Murphy, 2015) become enacted and enlisted in gendered sociomaterial change.

\section{Acknowledgments}

We are grateful to our interviewees, who generously shared their knowledge and memories with us. The seminar group Technology, Practice, Identity (P6) at the Department of Thematic Studies - Technology and Social Change provided valuable suggestions at an early stage of 
writing for which we are thankful. Our thanks also go to Professor Berndt Ehinger for providing us with the blood centre images and to the anonymous reviewers for their detailed and very useful comments.

\section{References}

Akrich M (1998) Les utilisateurs, acteurs de l'innovation. Education Permanente 138: 79-90.

Amsterdamska O (2008) Practices, places, and people. In: Hackett EJ, Amsterdamska O, Lynch $\mathrm{M}$ and Wajcman J (eds) The Handbook of Science and Technology Studies. Cambridge, MA: MIT Press.

Barcet A, Le Bas C and Mercier C (1985) Savoir-faire et Changements Techniques: Essai d'Economie du Travail Industriel. Lyon: Presses Universitaires de Lyon.

Barley SR (1996) Technicians in the workplace: Ethnographic evidence for bringing work into organizational studies. Administrative Science Quarterly 41(3): 404-444.

Barley SR (2005) What we know (and mostly don't know) about technical work. In: Ackroyd S, Batt R, Thompson P and Tolbert PS (eds) The Oxford Handbook of Work \& Organization. Oxford: Oxford University Press, 376-403.

Barley SR and Bechky BA (1996) In the backrooms of science: The work of technicians in science labs. Work and Occupations 21(1): 85-126.

Barley SR and Orr JE (1997) Introduction: The neglected workforce. In: Barley SR and Orr JE (eds) Between Craft and Science: Technical Work in US Settings. Ithaca: Cornell University Press.

Bartlett A (2008) Accomplishing Sequencing the Human Genome. Doctoral thesis, Cardiff University.

Berner B (2008) Working knowledge as performance: On the practical understanding of machines. Work, Employment and Society 22 (2): 319-336.

Berner B (2011) The making of a risk object: AIDS, gay citizenship and the meaning of blood donation in Sweden in the early 1980s. Sociology of Health and Illness 33(3): 384-398.

Berner B (2012) Blodflöden. Blodgivning och Blodtransfusion i det Svenska Samhället. Lund: Arkiv.

Blackler F (1995) Knowledge, knowledge work and organization. Organization Studies 16 (6): $1021-1046$. 
Bowker GC and Star SL (1999) Sorting Things Out: Classification and Its Consequences. Cambridge, MA: The MIT Press.

Casper MJ and Clarke AE (1998) Making the Pap smear into the 'right tool' for the job: Cervical cancer screening in the USA, circa 1940-95. Social Studies of Science 28(2): 255290.

Cook SDN and Brown JS (1999) Bridging epistemologies: The generative dance between organizational knowledge and organizational knowing. Organization Science 10(4): 381-400.

Deutsch FM (2007) Undoing gender. Gender \& Society 21(1): 106-127.

Doing P (2004) 'Lab hands' and the 'Scarlet O': Epistemic politics and (scientific) labor. Social Studies of Science 34(3): 299-323.

Duguid P (2005) 'The art of knowing': Social and tacit dimensions of knowledge and the limits of the community of practice. The Information Society 21(2): 109-18.

Espeland W (1984) Blood and money: Exploiting the embodied self. In: Kotarba JA and Fontan A (eds) The Existential Self in Society. Chicago: The University of Chicago Press.

Farrugia A (2011) Falsification or paradigm shift? Toward a revision of the common sense of transfusion. Transfusion 51(1): 216-224.

Faulkner W (2000) The power and the pleasure? A research agenda for 'making gender stick' to engineers. Science, Technology and Human Values 25(1): 88-120.

Garforth L and Kerr A (2010) Let's get organised: Practicing and valuing scientific work inside and outside the laboratory. Sociological Research Online 15(2) 11.

Gerson JM and Peiss K (1985) Boundaries, negotiation, consciousness: Reconceptualizing gender relations. Social Problems 32(4): 317-331.

Gherardi S and Perrotta M (2013) Doing by inventing the way of doing: Formativeness as the linkage of meaning and matter. In: Carlile PR, Nicolini D, Langley A, and Tsoukas H (eds) How Matter Matters: Objects, Artifacts, and Materiality in Organization Studies. Oxford: Oxford University Press.

Hartley JM and Tansey EM (2014) White coats and no trousers: Narrating the experiences of women technicians in medical laboratories, 1930-1990. Notes and Records of the Royal Society; 69(1). 
Healy K (2000) Embedded altruism: Blood collection regimes and the European Union's donor population. American Journal of Sociology 105(6): 1633-1657.

Herman C (2015) Rebooting and rerouting: Women's articulations of frayed careers in science, engineering and technology professions. Gender, Work and Organizations 22(4): 324-338.

Högman CF and Johansson A (1981) Simple method for the preparation of microaggregate-poor whole blood. Vox Sanguinis 40(4): 286-288.

Högman CF, Johansson A and Bergius B (1982) A simple method for the standardization of centrifugation procedures in blood component preparation. Vox Sanguinis 43(5): 266-269.

Högman C F, Eriksson L, Hedlund K and Wallvik J (1988) The bottom and top system: A new technique for blood component preparation and storage. Vox Sanguinis 55(4): 211-217.

Johansson A et al. (1982) Device for blood separation. US Patent 4,350,585, filed September 21, 1982.

Jones M (2013) Untangling sociomateriality. In: Carlile PR, Nicolini D, Langley A and Tsoukas H (eds) How Matter Matters: Objects, Artifacts, and Materiality in Organization Studies. Oxford: Oxford University Press.

Keefe J and Potosky D (1997) Technical dissonance: Conflicting portraits of technicians. In: Barley SR and Orr JE (eds) Between Craft and Science: Technical Work in US Settings. Ithaca: Cornell University Press.

Leonardi PM (2012) Materiality, sociomateriality, and socio-technical systems: What do these terms mean? How are they different? Do we need them? In: Leonardi PM, Nardi BA and Kallinikos J (eds) Materiality and Organizing: Social Interaction in a Technological World. Oxford: Oxford University Press.

Messeter L and Löw B (1977) Automated blood grouping of patients and blood donors using Groupamatic 360 S and a separate mini-computer. Vox Sanguinis 33(2): 116-123.

Muller A, Garretta M and Hebert M (1981) Groupamatic system: Overview, history of development and evaluation of use. Vox Sanguinis 40(3): 201-213.

Murphy M (2015) Unsettling care: Troubling transnational itineraries of care in feminist health practices. Social Studies of Science 45(5): 717-737.

Nentwich JC and Kelan EK (2014) Towards a topology of 'doing gender': An analysis of empirical research and its challenges. Gender, Work and Organization 21(2): 121-134. 
Orr EJ (1996) Talking about Machines: An Ethnography of a Modern Job. Ithaca: Cornell University Press.

Packer K (1996) The context-dependent nature of the gendering of technical work: A case study of work in a scientific laboratory. Work, Employment and Society 10(1): 125-149.

Pecis L (2016) Doing and undoing gender in innovation: Femininities and masculinities in innovation processes. Human Relations 69(11): 2117-2140.

Puig de la Bellacasa MP (2011) Matters of care in technoscience: Assembling neglected things. Social Studies of Science 41(1): 85-106.

Russell NC, Tansey EM and Lear PV (2000) Missing links in the history and practice of science: Teams, technicians and technical work. History of Science 38: 237-241.

Ryan GW and Bernard HR (2003) Techniques to identify themes. Field Methods 15(1): 85 -109.

Scarselletta M (1993) Button Pushers and Ribbon Cutters: Observations on Skill and Practice in a Hospital Laboratory and Their Implications for the Shortage of Skilled Technicians. : National Center on the Educational Quality of the Work Force. Philadelphia: University of Pennsylvania.

Scarselletta M (1997) The infamous 'lab error': Education, skill, and quality in medical technicians' work. In: Barley SR and Orr J (eds) Between Craft and Science: Technical Work in US Settings. Ithaca: Cornell University Press.

Shapin S (1989) The invisible technician. American Scientist 77(6): 554-563.

Starr D (1998) Blood: An Epic History of Medicine and Commerce. New York: Knopf.

STU (1979) STU-symposium i Skokloster 1979. Blod och Blodprodukter, STU-information 140, Stockholm: Styrelsen för teknisk utveckling.

STU (1985) Sammanfattande Rapport. Blod och Blodprodukter. STU-information 509, Stockholm: Styrelsen för teknisk utveckling.

STU (1986) Summarical Report. Blood and Blood Products. STU-information 555, Stockholm: Styrelsen för teknisk utveckling.

Suchman L, Trigg R and Blomberg J (2002) Working artefacts: Ethnomethods of the prototype. British Journal of Sociology 53(2): 163-179.

Timmermans S and Berg M (1997) Standardization in action: Achieving local universality through medical protocols. Social Studies of Science 27(2): 273-305. 
Torbica N and Krstev S (2006) World at work: Dental laboratory technicians. Occupational and Environmental Medicine 63(2): 145-148.

Truss C, Conway E, d'Amato A, Kelly G, Monks K, Hannon E and Flood PC (2012)

Knowledge work: gender-blind or gender-biased? Work, Employment and Society 26(5): 735754.

Wajcman J (2004) Technofeminism. Cambridge, UK: Polity Press.

Wylie CD (2014) 'The artist's piece is already in the stone': Constructing creativity in palaeontology laboratories. Social Studies of Science 45(1): 31-55.

\section{Author biographies}

Boel Berner is a professor emerita at the Department of Thematic Studies - Technology and Social Change, Linköping University, Sweden. Her research includes studies of technical expertise, education and work, often with a gender perspective. Her recent work concerns histories of blood donation and transfusion, and the entanglements of race, sex and blood group research in the Interwar years.

Maria Björkman is a researcher at the Department of History of Science and Ideas, Uppsala University, Sweden. Her research concerns the relations between eugenics and genetics, the emergence of genetic counselling, the history of scientific racism and how technology affects changes in medical practice, especially in urology.

\section{Notes}

1 There have been a few studies of technicians in blood services. In particular, Espeland (1984) has looked at technicians in US plasmapheresis centres, focusing mainly on their interactions with donors. Barley and Bechky (1996) and Scarselletta $(1993,1997)$ studied technicians' work with, for example, blood analysis, though not focusing specifically on blood banks.

2 Part of this 'paradigm change' was the new threat of HIV contamination. It made for a more stringent donor selection (see Berner, 2011) but did not change the practices detailed in this article until the mid-1980s.

3 We have used scientific articles, patent records, technical handbooks, trade journals and documents published within the STU programme, as well as unpublished documents from the STU archives at the Swedish National Archives, from the Regional Blood Centres' Coordination Committee (RBS), the Swedish Board of Health and Welfare, and the County Councils' Archive.

4 RBS, Minutes, 18 February 1988. 
5 Mouth pipetting is the practice of using one's mouth to suck a desired volume of a medical laboratory specimen - blood, urine, cell cultures etc. - into an open-ended tube, using the reduced air pressure created by sucking to hold the specimen in place while moving it to another vessel.

${ }_{6}$ Cf. Espeland's study (1984) of private US plasmapheris centres. She depicts a very detailed regulation that, in principle, was to steer all local activity, from the temperature of the freezer to how forms were filled in and the exact motions to be used by technicians when drawing blood and testing plasma donors. Local technicians, however, often circumvented the rules because they were not applicable in a certain situations, or because they needed to get a stressful job done. 